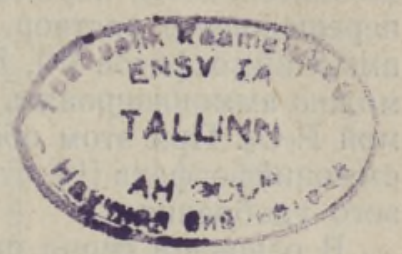

\title{
ПОЛУЧЕНИЕ РАЗНЫХ МАРОК НИТРОФОСКИ ИЗ РАКВЕРЕСКОГО ФОСФОРИТНОГО КОНЦЕНТРАТА С ВЫСОКИМ СОДЕРЖАНИЕМ МАГНИЯ
}

Раквереский фосфоритоносный район в Эстонской ССР является перспективным источником фосфатного сырья для производства минеральных удобрений. Судя по опытным образцам, состав раквереских фосфоритов различается содержанием примесей. Например, около 1/3 запасов фосруды участка Кабала, намеченного к первоочередному освоению, характеризуется повышенным содержанием магния. Полученный из этой руды фосфоритный концентрат относится в основном к ферроидно-магнезиальному типу ['], малопригодному для получения аммофоса и двойного суперфосфата. Однако такое сырье возможно использовать в процессах азотнокислотной переработки [ $\left.{ }^{2}\right]$. В условиях Эстонской ССР особый интерес представляет азотносернокислотно-сульфатный способ получения нитрофоски, предусмотренный для переработки фосфатного сырья на заводе минеральных удобрений ПО «Сланцехим». С применением апатита этот способ уже проверен на опытно-промышленной установке [ $\left.{ }^{3}\right]$, а с ракверескими фосконцентратами проведены лишь первые лабораторные эксперименты [4,5]. При переработке ферроидно-магнезиального фосфорита в заданных условиях было достигнуто извлечение $\mathrm{P}_{2} \mathrm{O}_{5}$ на $90 \%$, а в готовой нитрофоске отношение $\mathrm{P}_{2} \mathrm{O}_{5}: \mathrm{N}$ составило $0,8\left[{ }^{5}\right]$.

В настоящей работе более подробно изучали переработку ферроидно-магнезиального фосфорита в нитрофоску в целях достижения более высокой степени извлечения $\mathrm{P}_{2} \mathrm{O}_{5}$, а также получения продукта разных марок (в частности, с отношением $\mathrm{P}_{2} \mathrm{O}_{5}: \mathrm{N}=1: 1$ ). Фосфоритный концентрат, полученный анионной флотацией из руды участка Кабала, содержал 26,1\% $\mathrm{P}_{2} \mathrm{O}_{5}$ и $3,7 \%$ MgO. Модули примесей этого сырья были следующие, $\%: \frac{\mathrm{MgO}}{\mathrm{P}_{2} \mathrm{O}_{5}}=14,0 ; \frac{\text { пиритная } \mathrm{Fe}_{2} \mathrm{O}_{3}}{\mathrm{P}_{2} \mathrm{O}_{5}}=0,4 ; \frac{\text { непиритная } \mathrm{Fe}_{2} \mathrm{O}_{3}}{\mathrm{P}_{2} \mathrm{O}_{5}}=5,2$, а содержание ситовой фракции +180 мкм равнялось $36,7 \%$. Разложение фосфорита проводили смесью чистых реагентов $\mathrm{HNO}_{3}+\mathrm{H}_{2} \mathrm{SO}_{4}+$ $+\left(\mathrm{NH}_{4}\right)_{2} \mathrm{SO}_{4}$ в течение 1 ч при температуре $75^{\circ} \mathrm{C}$. Соотношение масс жидкой и твердой фаз в пульпе составляло в среднем $2,8: 1$. Для подавления выделения оксидов азота в реактор добавляли карбамид из расчета 10 г на 1000 г фосфорита [4]. В целях определения потерь $\mathrm{HNO}_{3}$ выделяющиеся газы абсорбировали раствором перекиси водорода. Реакционную пульпу отфильтровывали, осадок (фосфогипс) промывали водой. Основной фильтрат перерабатывали в нитрофоску путем аммонизации, упаривания, добавления $\mathrm{KCl}$ и сушки. Количество хлористого калия соответствовало отношению в продукте $\mathrm{P}_{2} \mathrm{O}_{5}: \mathrm{K}_{2} \mathrm{O}=1: 1$.

Фосфатное сырье, промежуточные продукты и готовую нитрофоску анализировали методами, изложенными в [6-9].

Предварительные опыты показали, что при использовании стехиометрической нормы кислоты, несмотря на варьирование отношения $\mathrm{HNO}_{3}$ : $\mathrm{H}_{2} \mathrm{SO}_{4}$, увеличение продолжительности перемешивания и применение 
ретура жидкой фазы, степень извлечения $\mathrm{P}_{2} \mathrm{O}_{5}$ не превышала $87-90 \%$. Магний извлекался в жидкую фазу на $80-98 \%$, а железо - на 50 $55 \%$ при одночасовом разложении фосфорита и всего на $5 \%$ при продолжительности перемешивания 4 ч. По-видимому, железо, вначале перешедшее в раствор, постепенно выпадает в осадок в виде железоаммонийфосфатов $\left[{ }^{10}\right]$. Было также установлено, что основной фильтрат можно аммонизировать до $\mathrm{pH} 6$ без существенной ретроградации усвояемой $\mathrm{P}_{2} \mathrm{O}_{5}$. При этом обеспечивается осаждение магния в виде магнийаммонийфосфата [ $\left.{ }^{11}\right]$, что способствует снижению гигроскопичности готового удобрения.

В основной серии опытов с целью увеличения степени извлечения $\mathrm{P}_{2} \mathrm{O}_{5}$ норму $\mathrm{H}^{+}$-иона кислот повышали до $110 \%$ от стехиометрической, а норму сульфат-иона поддерживали равной $100 \%$. Для получения нитрофоски разных марок норму $\mathrm{HNO}_{3}$ варьировали в пределах $30-110 \%$, a норму $\mathrm{H}_{2} \mathrm{SO}_{4}$ и $\left(\mathrm{NH}_{4}\right)_{2} \mathrm{SO}_{4}$ - в пределах $80-0$ и $20-100 \%$ соответственно. Остальные условия экспериментов не отличались от описанных. Основной фильтрат аммонизировали до $\mathrm{pH} 6$ и перерабатывали в нитрофоску.

Исследованиями установлено, что практически во всех вышеуказанных диапазонах изменения норм реагентов и на всех технологических стадиях процесс протекал нормально; готовые образцы нитрофоски обладали удовлетворительным качеством (таблица).

\section{Показатели получения нитрофоски}

\begin{tabular}{|c|c|c|c|c|c|c|c|}
\hline \multirow{2}{*}{ Показатели } & \multicolumn{7}{|c|}{ Номер опыта } \\
\hline & 1 & 2 & 3 & 4 & 5 & 6 & 7 \\
\hline \multicolumn{8}{|l|}{$\begin{array}{l}\text { Количество реагентов в } \\
\text { отношении к стехиометри- } \\
\text { ческой норме, \%: }\end{array}$} \\
\hline $\begin{array}{l}\mathrm{HNO}_{3} \\
\mathrm{H}_{2} \mathrm{SO}_{4} \\
\left(\mathrm{NH}_{4}\right)_{2} \mathrm{SO}_{4}\end{array}$ & $\begin{array}{l}30 \\
80 \\
20\end{array}$ & $\begin{array}{l}40 \\
70 \\
30\end{array}$ & $\begin{array}{l}50 \\
60 \\
40\end{array}$ & $\begin{array}{l}60 \\
50 \\
50\end{array}$ & $\begin{array}{l}70 \\
40 \\
60\end{array}$ & $\begin{array}{l}90 \\
20 \\
80\end{array}$ & $\begin{array}{r}110 \\
0 \\
100\end{array}$ \\
\hline $\begin{array}{l}\text { Потери } \mathrm{HNO}_{3} \text { на } 1000 \mathrm{r} \\
\text { фосфорита, r }\end{array}$ & 0,44 & 0,48 & 0,60 & 0,47 & 0,46 & 0,53 & 0,61 \\
\hline $\begin{array}{l}\text { Степень извлечения } \mathrm{P}_{2} \mathrm{O}_{5}, \% \\
\text { Скорость фильтрации, }\end{array}$ & 92,0 & 93,9 & 93,2 & 95,1 & 95,7 & 96,8 & 96,3 \\
\hline $\mathrm{M}^{3} / \mathrm{M}^{2} \cdot \mathrm{q}$ & 1,50 & 1,31 & 1,34 & 1,33 & 1,40 & 1,37 & 1,65 \\
\hline $\begin{array}{l}\text { Содержание в нитрофоске, } \\
\%:\end{array}$ & & & & & & & \\
\hline $\begin{array}{l}\text { общей } \mathrm{P}_{2} \mathrm{O}_{5} \\
\text { усвояемой } \mathrm{P}_{2} \mathrm{O}_{5} \\
\text { водорастворимой } \mathrm{P}_{2} \mathrm{O}_{5} \\
\text { водорастворимого } \mathrm{N}\end{array}$ & $\begin{array}{l}17,0 \\
16,7 \\
15,4 \\
15,2\end{array}$ & $\begin{array}{l}15,9 \\
15,6 \\
14,4 \\
16,1\end{array}$ & $\begin{array}{l}15,2 \\
14,9 \\
14,0 \\
17,4\end{array}$ & $\begin{array}{l}13,8 \\
13,6 \\
12,3 \\
19,0\end{array}$ & $\begin{array}{l}12,9 \\
12,7 \\
11,4 \\
19,8\end{array}$ & $\begin{array}{l}11,2 \\
10,9 \\
10,1 \\
21,2\end{array}$ & $\begin{array}{r}10,6 \\
9,9 \\
9,1 \\
22,6\end{array}$ \\
\hline $\begin{array}{l}\text { в том числе: } \\
\text { аммиачного } \\
\text { нитратного }\end{array}$ & $\begin{array}{r}10,5 \\
4,7\end{array}$ & $\begin{array}{r}10,4 \\
5,7\end{array}$ & $\begin{array}{r}10,5 \\
6,9\end{array}$ & $\begin{array}{r}11,6 \\
7,4\end{array}$ & $\begin{array}{r}11,7 \\
8,1\end{array}$ & $\begin{array}{r}12,1 \\
9,1\end{array}$ & $\begin{array}{l}12,6 \\
10,0\end{array}$ \\
\hline $\begin{array}{l}\text { водорастворнмой } \mathrm{K}_{2} \mathrm{O} \\
\text { питательных веществ }\end{array}$ & $\begin{array}{l}16,6 \\
48,8\end{array}$ & $\begin{array}{l}16,0 \\
48,0\end{array}$ & $\begin{array}{l}14,7 \\
47,3\end{array}$ & $\begin{array}{l}14,0 \\
46,8\end{array}$ & $\begin{array}{l}13,2 \\
45,9\end{array}$ & $\begin{array}{l}11,7 \\
44,1\end{array}$ & $\begin{array}{l}10,0 \\
43,2\end{array}$ \\
\hline $\begin{array}{l}\text { Отношение в нитрофоске, \% } \\
\left(\text { усв. } \mathrm{P}_{2} \mathrm{O}_{5}\right):\left(\text { общ. } \mathrm{P}_{2} \mathrm{O}_{5}\right) \\
\left(\text { вод. } \mathrm{P}_{2} \mathrm{O}_{5}\right):\left(\text { общ. } \mathrm{P}_{2} \mathrm{O}_{5}\right) \\
\left.\text { (общ. } \mathrm{P}_{2} \mathrm{O}_{5}\right):(\mathrm{N})\end{array}$ & $\begin{array}{r}98 \\
90 \\
112\end{array}$ & $\begin{array}{l}98 \\
90 \\
99\end{array}$ & $\begin{array}{l}98 \\
92 \\
87\end{array}$ & $\begin{array}{l}99 \\
90 \\
73\end{array}$ & $\begin{array}{l}98 \\
88 \\
65\end{array}$ & $\begin{array}{l}97 \\
90 \\
53\end{array}$ & $\begin{array}{l}93 \\
86 \\
47\end{array}$ \\
\hline
\end{tabular}

Степень извлечения $\mathrm{P}_{2} \mathrm{O}_{5}$ составляла $92-97 \%$, увеличиваясь с повышением нормы $\mathrm{HNO}_{3}$ (рисунок, кривая 1). В то же время выход фосфогипса снижался (кривая 2) за счет лучшей растворимости гипса в при- 
сутствии $\mathrm{NH}_{4} \mathrm{NO}_{3}\left[{ }^{12}\right]$. Железо извлекалось в жидкую фазу на $52-55 \%$, магний - практически полностью.
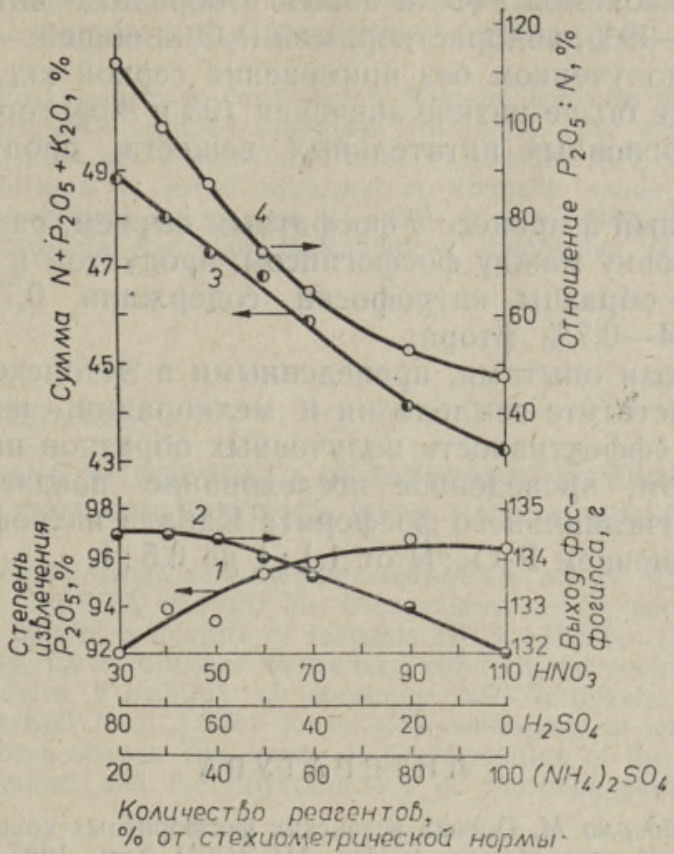

Зависимость показателей процесса от состава смеси реагентов.

На стадии разложения фосфорита наблюдалось умеренное нагревание пульпы (на $5-7^{\circ} \mathrm{C}$ ). Вспенивание пульпы было незначительное, добавление пеногасителя не требовалось. Потери оксидов азота в газовую фазу составляли $0,4-0,6$ г $\mathrm{HNO}_{3}$ на 1000 г фосфорита, что сравнимо с потерями в случае применения ковдорского апатита $\left[{ }^{13}\right]$. Пульпа была текучей и удовлетворительно фильтровалась. Скорость фильтрации при промывке фосфогипса составляла 1,3-1,6 $\mathrm{m}^{3} / \mathrm{m}^{2} \cdot$ ч - это несколько выше, чем в экспериментах по переработке апатитов в аналогичных условиях $\left[{ }^{13}\right]$. Промытый фосфогипс содержал $41-45 \%$ гигроскопичной влаги и, после сушки при $75^{\circ} \mathrm{C}$, около $18 \%$ кристаллизационной воды, что отвечает наличию двуводного сульфата кальция. Длина кристаллов гипса была в пределах 25-150 мкм.

Продукционный фильтрат содержал 6,2-6,5\% $\mathrm{P}_{2} \mathrm{O}_{5}$, имел отношение $\mathrm{Fe}_{2} \mathrm{O}_{3}: \mathrm{P}_{2} \mathrm{O}_{5}$ и $\mathrm{MgO}: \mathrm{P}_{2} \mathrm{O}_{5}$, соответственно, 2,5-3 и $13-15 \%$. Аммонизация фильтрата сопровождалась нагреванием его на $30-40^{\circ} \mathrm{C}$. При этом потерь аммиака не наблюдалось. Однако на стадии сушки нитрофоски его потери были ощутимые - по балансу азота около $10 \%$ от введенного количества.

По результатам химического анализа состав нитрофоски с увеличением нормы $\mathrm{HNO}_{3}$ от 30 до $110 \%$ изменялся следующим образом (см. таблицу):

- содержание общей $\mathrm{P}_{2} \mathrm{O}_{5}$ снижалось от 17,0 до $10,6 \%$ и водорастворимой $\mathrm{K}_{2} \mathrm{O}$ - от 16,6 до $10,0 \%$,

- содержание азота увеличивалось от 15,2 до $22,6 \%$,

- содержание суммы питательных веществ снижалось от 48,8 до $43,2 \%$ (рисунок, кривая 3 ),

- отношение $\mathrm{P}_{2} \mathrm{O}_{5}: \mathrm{N}$ снижалось от 112 до $47 \%$ (кривая 4),

- доля аммиачного азота от общего снижалась от 69 до $56 \%$. 
Нитрофоску марки 1:1:1 получили при норме $\mathrm{HNO}_{3}, \mathrm{H}_{2} \mathrm{SO}_{4}$ и $\left(\mathrm{NH}_{4}\right)_{2} \mathrm{SO}_{4} 40,70$ и $30 \%$ соответственно.

Отношение усвояемой $\mathrm{P}_{2} \mathrm{O}_{5}$ к общей в образцах нитрофоски составляло обычно $98-99 \%$, водорастворимой $\mathrm{P}_{2} \mathrm{O}_{5}$ к общей - $88-92 \%$. Только в продукте, полученном без применения серной кислоты, указанные показатели имели более низкие значения ( 93 и $86 \%$ соответственно).

Кроме трех основных питательных веществ, продукты содержали $1,5-2,5 \%$ MgO.

Фтор, введенный в процесс с фосфатным сырьем, распределялся приблизительно поровну между фосфогипсом, продуктом и выделяющимися газами. Готовые образцы нитрофоски содержали $0,7-0,8 \%$, а сухой фосфогипс - 0,4-0,7\% фтора.

Вегетационными опытами, проведенными в Эстонском научно-исследовательском институте земледелия и мелиорации, показана высокая агрохимическая эффективность полученных образцов нитрофоски.

Таким образом, проведенное исследование показало возможность получения из магнезиального фосфорита Кабала нитрофоски различных марок - с отношением $\mathrm{P}_{2} \mathrm{O}_{5}: \mathrm{N}$ от $1,1: 1$ до $0,5: 1$.

\section{ЛИТ Е РА Т Р А}

1. Аасамяэ Э., Вейдерма М. Оценка эстонскнх фосфоритных концентратов как сырья для кислотной переработки. - Изв. АН ЭССР. Хим., 1983, 32, № 4, 242-245.

2. Кармышов В. Ф. Химическая переработка фосфоритов. М., 1983.

3. Абашкина Т. Ф., Шмульян Е. К., Одерберг А. С., Отрешко В. М., Товстюк Л. М. Лифииц М. С. Разработка способа получения высококонцентрированных водорастворимых удобрений способом азотно-сернокислотного разложения апатита. - Тр НИУИФа, вып. 221. М., 1973, $121-127$.

4. Аасамяэ Э., Вейдерма М. Азотнокислотно-сульфатная переработка фосфоритов Раквереского месторождения. - Изв. АН ЭССР. Хим., 1984, 33, № 2, 73-78.

5. Аасамяэ Э., Вейдерма М. Получение нитрофоски из раквереских фосфоритов азотнокислотно-сульфатным способом. - Изв. АН ЭССР. Хим., 1985, 34, № 3 , $165-169$.

6. Методы анализа фосфатного сырья, фосфорных и комплексных удобрений, кормовых фосфатов. М., 1975.

7. McBride, C. H. Determination of secondary and minor plant nutrients in fertilizers by atomic absorption. Spectrophotometry: third collaborative study. - J. Assoc. Offic. Anal. Chem., 1967, 50, N 2, 401-407.

8. Окнина В. А. Методы химического анализа фосфатных руд. М., 1961.

9. Bremner, J. M., Keeney, D. Steam destillation methods for determination of ammonium, nitrate and nitrite. - Anal. Chim. Acta, 1965, 32, N 5, 485-495.

10. Марголис Ф. Г., Кармышов В. Ф., Глазова Т. В., Франчук Н. П., Портнова Н. Л. Изучение части изотермы в системе $\mathrm{Fe}_{2} \mathrm{O}_{3}-\mathrm{P}_{2} \mathrm{O}_{5}-\mathrm{N}_{2} \mathrm{O}_{5}-\left(\mathrm{NH}_{4}\right)_{2} \mathrm{O}-\mathrm{H}_{2} \mathrm{O}$ при $55^{\circ} \mathrm{C}$. - Тр. НИУИФа, вып. 221. М., 1973, 46-55.

11. Шмульян Е. К., Портнова Н. Л., Дорошина Т. В., Абашкина Т. Ф., Винник М. М., Красильникова И. Г. Соединения, образующиеся при аммонизации нитрофосфатных растворов, полученных переработкой фосфорита Каратау. - Тр. НИУИФа, вып. 231. М., 1977, 167-172.

12. Крученко В. П. Растворимость гипса в системе $\mathrm{CaSO}_{4}-\mathrm{H}_{3} \mathrm{PO}_{4}-\mathrm{NH}_{4} \mathrm{NO}_{3}-\mathrm{H}_{2} \mathrm{O}$ при 25,40 и $60{ }^{\circ} \mathrm{C}$. - В кн.: Физнко-химические исследования сложных систем. Алма-Ата, $1981,8-15$.

13. Аасамяэ Э., Вейдерма М. Влияние добавки карбамида на азотнокислотно-сульфатную переработку природных фосфатов. - Изв. АН ЭССР. Хим., 1983, 32, № 1 , $1-7$.

Таллинский политехнический институт 


\section{ERINEVA KOOSTISEGA NITROFOSKA SAAMINE KORGE MAGNEESIUMI- SISALDUSEGA RAKVERE FOSFORIIDIST}

On uuritud nitrofoska saamist, lagundades Rakvere leiukoha fosforiidikontsentraati $\mathrm{HNO}_{3}, \mathrm{H}_{2} \mathrm{SO}_{4}$ ja $\left(\mathrm{NH}_{4}\right)_{2} \mathrm{SO}_{4}$ seguga, kusjuures fosfokipsi sade eraldati filtrimisega ja filtraat ammoniseeriti kuni $\mathrm{pH}$ 6. Kasutatav fosforiit sisaldas $26 \% \mathrm{P}_{2} \mathrm{O}_{5}$ ja $3,7 \%$ MgO. Katsete tulemused näitavad, et antud toorainest on võimalik saada erineva koostisega nitrofoskat, milles toimeainete sisaldus on $43-49 \%$ ja massisuhe $\mathrm{P}_{2} \mathrm{O}_{5}: \mathrm{N}$ piirides $0,5: 1$ kuni $1,1: 1 . \mathrm{P}_{2} \mathrm{O}_{5}$ eraldusaste fosforiidi lagundamisel moodustas $92-97 \%$ ja fosfokipsi filtritavus oli rahuldav.

\section{E. AASAMAE, M. VEIDERMA}

\section{OBTAINING NITROPHOSKA OF DIFFERENT COMPOSITION FROM THE RAKVERE PHOSPHORITE WITH HIGH MAGNESIUM CONTENT}

Obtaining nitrophoska from a phosphate concentrate of the Rakvere deposit, containing $26 \%$ of $\mathrm{P}_{2} \mathrm{O}_{5}$ and $3.7 \%$ of $\mathrm{MgO}$ has been studied in the paper. Phosphorite was decomposed with the help of a mixture of reagents $\mathrm{HNO}_{3}+\mathrm{H}_{2} \mathrm{SO}_{4}+\left(\mathrm{NH}_{4}\right)_{2} \mathrm{SO}_{4}$. Phosphogypsum was separated, the filtrate was neutralized with $\mathrm{NH}_{3}$ and evaporated; after adding $\mathrm{KCl}$ the slurry was dried. Possibility of obtaining NPK-fertilizers of various grades (weight ratio $\mathrm{N}: \mathrm{P}_{2} \mathrm{O}_{5}: \mathrm{K}_{2} \mathrm{O}$ from $1: 0.5: 1$ to $1: 1.1: 1$ ) containing in summary $43-49 \%$ of plant nutrients, has been shown. The degree of decomposition of the phosphorite as high as $92-97 \%$ was obtained and the filtration rate of phosphogypsum was found to be satisfactory. 